\title{
An Effective Way to Solve Equivocal Mammography Findings: The Rolled Views
}

\author{
Emel Alimoglu ${ }^{\mathrm{a}} \quad$ Kagan Ceken $^{\mathrm{a}} \quad$ Adnan Kabaalioglu $^{\mathrm{a}} \quad$ Enrico Cassano $^{\mathrm{b}} \quad$ Timur Sindel $^{\mathrm{a}}$ \\ aDepartment of Radiology, Akdeniz University, Faculty of Medicine Antalya, Turkey \\ ${ }^{\mathrm{b} B r e a s t}$ Imaging Unit, European Institute of Oncology, Milan, Italy
}

Key Words

Breast - Mammography, rolled view

\section{Summary}

Background: The aim of this study was to investigate the efficacy of the rolled views taken in craniocaudal (CC) and mediolateral oblique (MLO) projections in solving equivocal mammography findings. Patients and Methods: The rolled views were taken by changing the positioning of the breast but not the obliquity of the $X$-ray beams. The breast was rolled medially or laterally in the rolled CC view, and inferiorly or superiorly in the rolled MLO view to separate overlapping structures from each other. Results: We evaluated equivocal findings in 87 asymptomatic women undergoing either CC ( $n=48$, $55 \%$ ) or MLO ( $\mathrm{n}=39,45 \%$ ) rolled views between 2001 and 2008. The rolled views were helpful in solving equivocal mammographic findings and making proper decisions on management in 85 of the $87(97.7 \%)$ women. This technique was used for breast asymmetries in 55 of the $87(63.2 \%)$ women, and was sufficient to directly show summation artifacts in 59 of 79 (74.6\%) women. The rolled views revealed 4 intramammary lymph nodes, 2 circumscribed masses out of 6 obscured masses, 7 summation artifacts, and 2 circumscribed masses out of 9 questionable masses. Conclusions: The rolled view is an effective method of differentiating summation artifacts from real lesions on mammography in both the CC and the MLO view.
Schlüsselwörter

Brust - Mammographie, gerollte Aufnahme

\section{Zusammenfassung}

Hintergrund: Ziel dieser Studie war die Evaluierung des Stellenwertes der gerollten Aufnahmen bei der Abklärung von unklaren mammographischen Befunden im craniocaudalen (CC) und mediolateral-schrägen (MLO) Strahlengang. Patientinnen und Methoden: Die gerollten Aufnahmen wurden nach Veränderung der Lage der Brust und bei konstantem Röntgenstrahlengang aufgenommen. Die Brust wurde für die CC-Position nach mediolateral (gerollte CC-Aufnahme) und für die MLO-Position nach oben oder unten gerollt, um überlappende Strukturen voneinander zu trennen. Ergebnisse: Zwischen 2001 und 2008 wurden bei 87 asymptomatischen Patientinnen 48 (55\%) unklare Befunde mit einer gerollten Aufnahme in der CC-Position und 39 (45\%) unklare Befunde mit einer gerollten Aufnahme in der MLO-Position evaluiert. Bei 85 der 87 Patientinnen $(97,7 \%)$ führte die gerollte Aufnahme zur Abklärung des unklaren Befundes und unterstützte die Therapieentscheidung. Die Methode wurde bei 55 der 87 Patientinnen $(63,2 \%)$ zur Abklärung von Brustasymmetrien eingesetzt und konnte bei 59 von 79 Patientinnen (74,6\%) Summationsartefakte identifizieren. 9 suspekte Läsionen wurden mithilfe gerollter Aufnahmen evaluiert. Dabei wurden 4 intramammäre Lymphknoten, 2 umschriebene Tumoren (von 6 obskuren Neoplasien), 7 Summationsartefakte und 2 umschriebene Tumoren (von 9 fraglichen Neoplasien) aufgedeckt. Schlussfolgerungen: Gerollte Aufnahmen sind bei der Differenzierung von Summationsartefakten und echten Läsionen sowohl in der CC- als auch der MLO-Position effektiv.

\begin{tabular}{ll}
\hline KARGER & $\oplus$ 2010 S. Karger GmbH, Freiburg \\
Fax +497614520714 & Accessible online at: \\
$\begin{array}{l}\text { Information@Karger.de } \\
\text { www.karger.com }\end{array}$ & www.karger.com/brc
\end{tabular}




\section{Introduction}

In daily practice of mammography, questionable findings are encountered frequently. For example, summation artifacts mimicking architectural distortion, mass, or focal asymmetry lead to misdiagnosis. Radiologists have to decide whether any questionable appearance is a sign of a real lesion or an artifact before coming to a final decision. Definite diagnosis of summation artifacts or benign lesions on mammography prevents many unnecessary biopsies and mammographic follow-ups. Radiologists use additional mammographic methods such as spot compression, true lateral, tangential views, or changing the obliquity of the X-ray beams to solve questionable findings [1-5]. Sickles [6] described these special mammographic views as a 'shopping list' from which the radiologist may select the best approach in his/her sufficient experience to solve mammographic problems. The rolled craniocaudal (CC) view, an item in this shopping list, has been described in previous studies [7-9]. However, the rolled views taken in lateral projection have so far only been emphasized by Brenner [7], and there is no study investigating any additional value of the rolled view taken in the mediolateral oblique (MLO) projection in solving mammographic ambiguities. This paper demonstrates the rolled technique taken in two standard projections as an additional mammographic method, and aims to investigate its efficacy in a problem-solving setting.

\section{Patients and Methods}

\section{The Rolled View Technique}

The rolled view is described as changing the positioning of the breast but not the obliquity of the X-ray beams. This technique is performed in either the CC or the MLO position. In the CC position, the breast is rolled in either the medial or lateral direction. For example, while the upper part of the breast is rolled medially (from lateral to medial), the inner part changes its position laterally along the $\mathrm{X}$-axis of the breast (fig. $1 \mathrm{a}$ ). In the MLO position, the breast is rolled in either the inferior or superior direction. While the lateral part is rolled inferiorly (from superior to inferior), the medial part changes its position in the opposite direction (fig. $1 \mathrm{~b}$ ).

\section{Study Population}

We evaluated 87 asymptomatic patients with the rolled views between March 2001 and September 2008. The indications for the rolled view were: i) asymmetries seen on only 1 view, or focal asymmetries; ii) architectural distortions; iii) questionable masses; and iv) masses partially obscured by glandular tissue. The aim of the technique was to separate overlapping structures from each other. When it was not possible to move the equivocal finding to a fattier portion of the breast, for example when the breast was quite dense or the lucent-targeted area of the breast was too far away, we opted for a different additional method. The mammograms were obtained by screen film mammography (Philips Mammo Diagnost 3000, Philips Deutschland GmbH, Hamburg, Germany) between 2001 and 2005, and full-field digital mammography (Giotto, IMS, Bologna, Italy) after 2005. All of the rolled CC or MLO views were obtained during the patients' initial visits.

\section{Interpretation of the Mammograms and Follow-Up Protocol}

Mammograms were evaluated by a single radiologist with 9 years experience in breast radiology, and all patients were followed up by the same radiologist. The rolled views were interpreted as follows: When the equivocal mammographic finding disappeared on the rolled views, it was judged as a summation artifact (fig. 2; online supplemental material, www.karger.com/DOI=000313904). When the finding lost its previous suspicious characteristics, it was considered a focal deposit of benign fibroglandular tissue (fig. 3). When the method confirmed a focal asymmetry still present on rolled view or a real mass which was circumscribed but not showing typical characteristics of a fibroadenoma, a sonographic examination was performed for further exploration. Even if sonography was negative in breast asymmetries present on the rolled view, it was decided to follow up under BI-RADS 3. Patients having equivocal findings during routine mammography were accepted as BI-RADS 0 . These patients were included in a certain category after application of the rolled views. BI-RADS 3 lesions were monitored for at least 2 years at short intervals (6-month intervals by repeating only standard CC or MLO views for the first year and then annual follow-up). We preferred repeating the original standard view on which the abnormality was seen, in order to compare it with future standard films. Lesions remaining stable for more than 2 years were accepted as benign.

\section{Labeling}

We used specific labeling abbreviations standardized by the American College of Radiology on rolled CC mammograms [10]. For example, LCCRL+ means upper part of left breast tissue is rolled from medial to lateral (L: left, CC: craniocaudal projection, R: roll, L: laterally, +: upper part). We applied the same labeling technique for all rolled MLO views. For example, if the lateral tissue of the left breast was rolled inferiorly, this film was labeled as LMLRI+ (L: left, ML: MLO projection, R: roll, I: inferiorly, +: lateral tissue).
Fig. 1.a Rolled CC view of the left breast. In LCCRM+, while the upper part of the breast is rolled medially, the lower part is changing position from medial to lateral. In the same way, the upper part can be rolled laterally in LCCRL+ (L: left breast, CC: craniocaudal, R: roll, L: laterally, M: medially, +: upper tissue). b Rolled MLO view of the right breast. In RMLRS+, the outer or lateral part of the breast is rolled from inferior to superior. In the same way, the outer part can be rolled from superior to inferior in RMLRI+ (R: right breast, ML: MLO, R: roll, I: inferiorly, $\mathrm{S}$ : superiorly, +: lateral or outer tissue).
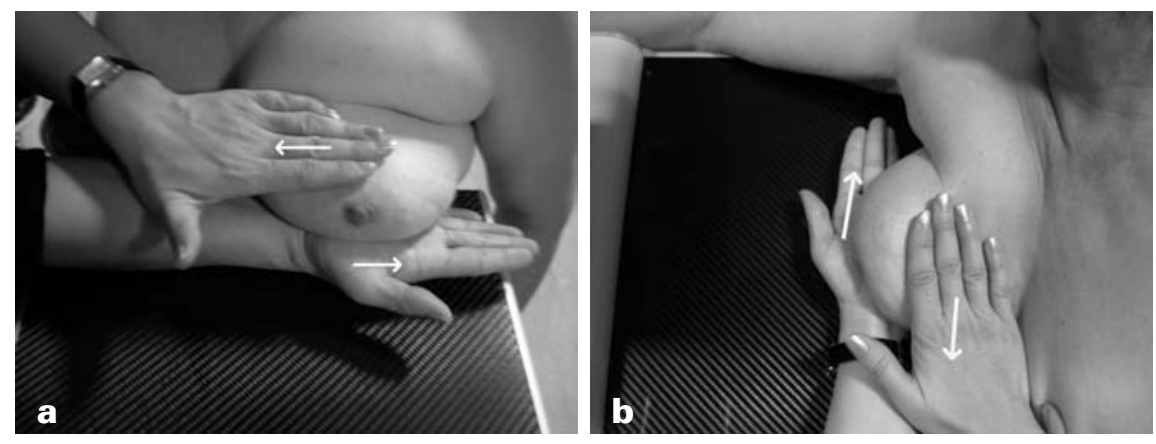
Fig. 3.a In the left $\mathrm{CC}$ view, a questionable mass is seen in the outer quadrant (arrow) b The upper-outer part of the breast is slightly rolled medially (from lateral to medial) in the LCCRM+ view. Because the equivocal mammographic finding lost its previously suspicious characteristics, it was considered a focal deposit of benign fibroglandular tissue, and this patient was categorized as BI-RADS 2 and invited to annual screenings. c Mammographic finding on left CC remained the same, even in the third year of follow-up, without any malignant progress.

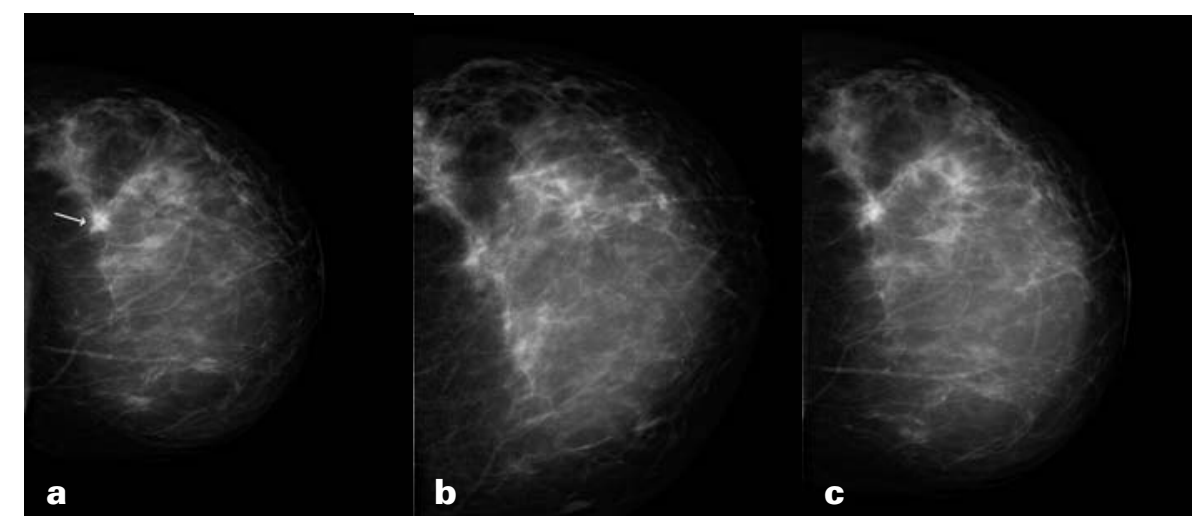

\section{Results}

We evaluated 87 equivocal mammographic findings in 87 asymptomatic women undergoing either the CC (n: 48, 55\%) or the MLO (n: 39, 45\%) rolled views between 2001 and 2008. The total number of additional views applied was 621 in the same period. Of all additional views, the frequency of the rolled views was calculated as $14.0 \%$. The method was successful in solving mammographic abnormality in 85 of 87 $(97.7 \%)$ women, and failed in $2(2.2 \%)$ of them. Six women were lost to routine mammographic screenings. One patient was advised to undergo a biopsy after the rolled view, because her lesion remained unchanged on the rolled view. Of the remaining 78 women, 13 were BI-RADS 3 (even though sonography dismissed the possibility of malignancy in 11 of them by showing only fibroglandular tissue), and 65 were BI-RADS 2. The 6 women who were lost to routine follow-ups had asymmetries seen only on 1 view. Since their asymmetries disappeared on the rolled view, they were accepted as BI-RADS 2 , bringing the total number of patients in this category to 71 $(81.6 \%)$. Figure 4 shows the distribution of the whole study population according to BI-RADS assessment categories.

The range of follow-up period was 24-60 months (mean: $35.1 \pm 12.3)$ in BI-RADS 3 patients. No malignant process was observed in these patients by the end of a 2-year follow-up period, and some remained normal even after 2 years. Similarly, the patients diagnosed as BI-RADS 2 have not developed any malignancy apparent at their routine visits for the last 8 years (fig. 5; online supplemental material, www.karger. com/DOI=000313904).

One patient who had been initially diagnosed as BI-RADS 3 was downgraded to BI-RADS 2 after 2 years of follow-up. Despite this improvement in her status, she underwent surgical biopsy after needle localization at her own request during her 5th check-up. The biopsy revealed 'flat epithelial atypia and fibrocystic changes'. Table 1 shows the mammographic findings of 79 lesions for which biopsy or sufficient follow-up results were available. The rolled views were used mostly in the evaluation of breast asymmetries in 47 women. Six women

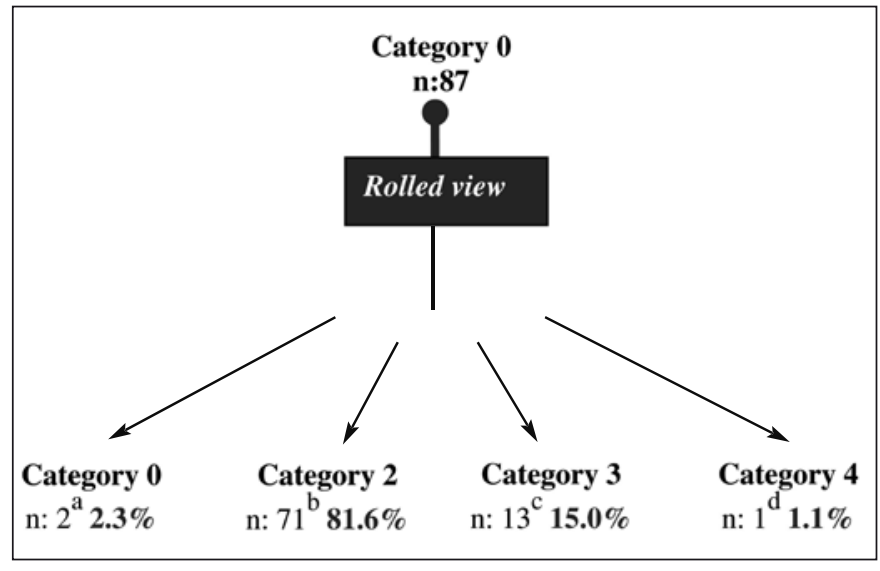

Fig. 4. Distribution of cases regarding BI-RADS assessment categories after rolled views.

${ }^{a}$ Both underwent spot compression and sonography as an additional method.

bix were lost to routine screenings; remaining 65 patients were stable on (1 or more) routine mammographic screenings.

'Thirteen were stable on 2-year follow-up or even later (some).

${ }^{\mathrm{d}}$ Biopsy revealed sclerosing adenosis.

who were lost to routine follow-ups and 2 women whose equivocal findings could not be resolved by rolled views had breast asymmetries on mammography. So, the number of breast asymmetries going to rolled views was 55 (63.2\%) in total. This technique was sufficient to show summation artifacts directly in 59 of 79 (74.6\%) women for whom we had either biopsy or sufficient follow-up results. The rolled CC views were used to solve the following mammographic problems: 19 focal asymmetries (12 rolled CC 63\%; 7 rolled MLO, $37 \%$ ), 28 asymmetries seen only 1 view (13 rolled CC, 46\%; 15 rolled MLO, 54\%), 9 questionable masses (4 rolled CC, $44 \%$; 5 rolled MLO, 56\%), 17 suspicious architectural distortions (7 rolled CC, 41\%; 10 rolled MLO, 59\%), and 6 obscured masses (4 rolled CC, 67\%; 2 rolled MLO, 33\%).

The rolled views taken in the CC or MLO position revealed 4 intramammary lymph nodes and 2 circumscribed masses ( 2 cysts in sonography) in 6 obscured masses. In addition, the rolled views solved diagnostic ambiguity in 9 ques- 
Table 1. Results of 79 lesions having either biopsy or sufficient follow-ups after rolled views

\begin{tabular}{|c|c|c|c|c|}
\hline \multirow[t]{3}{*}{ Equivocal findings } & \multicolumn{4}{|c|}{ Results of rolled views, $\mathrm{n}(\%)$} \\
\hline & \multicolumn{2}{|c|}{ benign (BI-RADS 2) } & \multirow{2}{*}{$\begin{array}{l}\text { probably benign } \\
\text { (BI-RADS 3) }\end{array}$} & \multirow{2}{*}{$\begin{array}{l}\text { probably malignant } \\
\text { (BI-RADS 4) }\end{array}$} \\
\hline & summation $^{\mathrm{a}}$ & mass & & \\
\hline Focal asymmetry $(\mathrm{n}=19)$ & $15(78.9)$ & & $3(15.7)$ & $1^{\mathrm{b}}(5.2)$ \\
\hline Asymmetry seen only 1 view $(n=28)$ & $25(89.2)$ & & $3(10.7)$ & \\
\hline Questionable mass $(n=9)$ & $7^{\mathrm{c}}(77.7)$ & & $2^{\mathrm{d}}(22.2)$ & \\
\hline Suspicious architectural distortion $(\mathrm{n}=17)$ & $12(70.5)$ & & $5(29.4)$ & \\
\hline Obscured mass $(\mathrm{n}=6)$ & & $6^{\mathrm{e}}(100)$ & & \\
\hline Total $(n=79)$ & $59(74.6)$ & $6(7.5)$ & $13(16.4)$ & $1(1.2)$ \\
\hline \multicolumn{5}{|l|}{ a'Disappeared completely on rolled views. } \\
\hline \multicolumn{5}{|l|}{ 'bclerosing adenosis found in biopsy. } \\
\hline \multirow{2}{*}{\multicolumn{5}{|c|}{$\begin{array}{l}\text { 'One 'flat epithelial atypia and fibrocystic changes' found in biopsy. } \\
\text { d'Two fibroadenoma-like solid masses on sonography. }\end{array}$}} \\
\hline & & & & \\
\hline \multicolumn{5}{|c|}{ é Four intramammary lymph nodes on mammography and 2 benign masses ( 2 cysts on sonography). } \\
\hline
\end{tabular}

tionable masses. Seven of them were summation artifacts (fig. 3), and 2 were circumscribed masses. All cases in BI-RADS 3 (n: 13) and 4 (n: 1) underwent sonography after rolled view. Also, 2 cases underwent sonography as the technique was not successful. Consequently, the total number of cases receiving sonography was 16 . In 1 case assessed BI-RADS 4, although sonography was negative, biopsy was recommended since the focal asymmetry remained unchanged. Biopsy revealed sclerosing adenosis in this case.

\section{Discussion}

The rolled views were helpful in solving equivocal mammographic findings and making proper decisions on the management of 85 out of $87(97.7 \%)$ women. The method prevented unnecessary biopsies and follow-ups in the study population assessed as BI-RADS 2.

In the rolled views, overlapping fibroglandular structures will no longer project over each other. The radiologist obtains high contrast with this maneuver. This technique was previously described for the CC position to demonstrate summation artifacts and evaluate overlapped images of masses. However, some suspicious findings may appear in only the MLO position. Brenner [7] was the first author who suggested that rolled views could also be performed in the lateral position in the evaluation of breast asymmetries. Although this method is well known by many radiologists, there is no published research in the literature about the application of this technique in the MLO position. To our knowledge, this is the first descriptive study investigating the diagnostic value of the rolled view taken in both the MLO and CC position as an additional mammographic method. In our study, the rolled MLO views were used effectively in $45 \%$ of cases. The rolled MLO views could be confidently performed in terms of technique compared to the rolled CC view. Our goal is to encourage breast imagers to use this technique in the MLO position as well.

Breast asymmetries are among commonly faced problems in mammography. The American College of Radiology
BI-RADS lexicon defines 4 different types of asymmetric breast findings: i) asymmetry (visible on only 1 standard view), ii) global asymmetry, iii) developing asymmetry, and iv) focal asymmetry $[2,10,11]$. The causes of breast asymmetries are mostly benign fibroglandular deposits with or without summation. However, malignant lesions may appear on mammograms with focal asymmetries. Sickles [12] studied 300 consecutive non-palpable breast cancers, and found focal asymmetry in $3 \%$ of cases. On the other hand, when asymmetric breast tissue is seen in only 1 standard view, it may lead to diagnostic confusion. We used the rolled views mostly for solving breast asymmetries (63.2\% of the study group). This technique showed summation artifacts directly in $74.6 \%$ of cases. Only 1 case was referred for biopsy, and was diagnosed as sclerosing adenosis. As is well-known, sclerosing adenosis may mimic carcinoma and require biopsy [13].

During routine screenings, radiologists may encounter masses the borders of which are obscured by benign fibroglandular tissue. We usually prefer to use sonography for further characterization of such masses, and although the rolled view technique is not the primary method of evaluation, we found 4 intramammary lymph nodes and 2 circumscribed masses in 6 obscured lesions. Since the number of patients with masses was limited in our study, further studies with larger groups are needed to show its real effectiveness.

Spot compression, magnification views, and sonography may be used as additional work-up for the same purpose $[4,5$, 14], but each additional method has limitations and advantages. For example, spot compression views may not solve the mammographic abnormality in deep areas adjacent to pectoral muscle, because it cannot move sufficient amounts of breast tissue. Furthermore, the radiologist may lose anatomic orientation on spot views because of the smallness of the area. The edges of the spot compression device may cause loss of information in adjacent areas [7]. In comparison, the rolled views can show the entire glandular tissue of the breast. Therefore, the radiologist can evaluate the mammographic findings without losing anatomic orientation. As for sonography, when sonography is negative, malignancy can not be 
excluded. Berg et al. [15] stated that 30 of 177 malignancies were negative on sonography. In the study of Brem et al. [16], the sensitivity of sonography for the detection of invasive lobular carcinoma was $68 \%$. Invasive lobular carcinomas may present with only subtle findings such as focal asymmetry or distortion on mammography. On the other hand, combining sonography with mammography will raise the sensitivity of breast cancer diagnosis. Berg et al. [15] reported the sensitivity of combined mammography and sonography (91.5\%) was better than that of each method separately. Taking into account all facts mentioned above, we combined the rolled views with sonography to evaluate breast asymmetries.

Which method is preferred under which condition depends on the location of the lesion, breast pattern, and experience of the radiologist. Pearson et al. [1] used the step oblique technique to show summation artifacts. In fact, both the step oblique and rolled view technique serve the same purpose. The difference between them is what is changed throughout the procedure. In the step oblique technique, the angle of the $\mathrm{X}$-ray beams is changed step by step. In our opinion, revealing summation artifacts by taking only 1 film is more practical. However, as mentioned before, the status of the lesion and experience of the radiologist are vital in selecting the additional method.

The rolled views have some technical limitations. First, it is not appropriate in dense breasts since it could lead to new summations. Second, limited mobility of breast tissue can be encountered in deeper regions close to the pectoral muscle and sternum, hindering repositioning of the breast in the medial/lateral or anterior/posterior direction. Another limitation is deep lesions that can be rolled off the image detector. Sonography or magnetic resonance imaging (MRI) may be preferred options for lesions located in deep areas. Also, this study has one limitation. We did not design the study to compare the methods used in evaluating breast asymmetries.
Thus, it is very difficult to provide the number of all breast asymmetries seen in our daily practice throughout the study period.

\section{Conclusion}

The rolled views were helpful in the management of $97.7 \%$ of patients, and revealed summation artifacts directly in $74.6 \%$ of cases. It is an effective method for differentiating summation artifacts from real lesions on mammography in both the $\mathrm{CC}$ and the MLO view. Furthermore, combining the rolled view with sonography in appropriate cases provides more accurate management and prevents unnecessary biopsies.

\section{Online Supplemental Figures}

Fig. 2. a In the MLO view of right breast, focal asymmetry is seen in a 49-year-old woman (arrow). b In RMLRS+, the outer part is rolled from superiorly, and the equivocal finding disappeared completely on rolled view. This lesion was accepted as a summation artifact, and annual screenings were recommended for this patient assessed as BI-RADS 2 after rolled view.

Fig. 5. Right $\mathrm{CC}$ rolled view in a 44-year-old woman. a Focal asymmetry seen on right $\mathrm{CC}$ view taken in 2002. b RCCRL+ view (right CC rolled from medial to lateral) revealed summation artifact. The patient was diagnosed as BI-RADS 2. c Focal asymmetry unchanged by 2005 and thereafter.

To access the supplemental figures please refer to www.karger.com/ DOI $=000313904$.

\section{Conflict of Interest}

All authors confirm that they don't have any conflict of interest.

\section{References}

1 Pearson KL, Sickles EA, Frankel SD, Leung JWT: Efficacy of step-oblique mammography for confirmation and localization of densities seen on only one standard mammographic view. AJR 2000;174:745-752.

2 Samardar P, Paredes ES, Grimes MM, Wilson JD: Focal asymmetric densities seen at mammography: US and pathologic correlation. Radiographics 2002;22:19-33.

$>3$ Logan WW, Janus J: Use of special mammographic views to maximize radiographic information. Radiol Clin North Am 1987;25:953-959.

$\checkmark 4$ Sickles EA: Successful methods to reduce falsepositive mammography interpretations. Radiol Clin North Am 2000;38:693-700.

$\checkmark 5$ Brenner JR: False-negative mammograms: medical, legal, and risk management implications. Radiol Clin North Am 2000;38:741-757.
6 Sickles EA: Practical solutions to common mammographic problems: tailoring the examination. AJR 1988;151:31-39.

7 Brenner JR: Strategies in the evaluation of breast asymmetries: extended use of the rolled view. Appl Radiol 1998;2:15-24.

8 Kopans DB: Mammographic positioning; in Kopans DB (ed): Breast Imaging, ed 3. Philadelphia, PA, Lippincott Williams and Wilkins, 2007, pp 316-317.

9 ACR (American College of Radiology): Labeling of Mammograms, Quality Control Manual, Clinical Image Section, reprinted 2007, pp 24.

10 D'Orsi CJ, Newell MS: BI-RADS decoded: detailed guidance on potentially confusing issues. Radiol Clin N Am 2007:45:751-763.

11 Sickles EA: The spectrum of breast asymmetries: imaging features, work-up, management. Radiol Clin N Am 2007;45:765-771.
12 Sickles EA: Mammographic features of 300 consecutive nonpalpable breast cancers. AJR Am J Roentgenol 1986;146:661-663.

13 Günhan I, Memi A, Ustün EE, Ozdemir N, Erhan Y: Sclerosing adenosis: mammographic and ultrasonographic findings with clinical and histopathological correlation. Eur J Radiol. 2002;44:232-238.

14 Berkowitz JE, Gatewood MB, Gayler BW: Equivocal mammographic findings: evaluation with spot compression. Radiology 1989;171:369-371.

15 Berg WA, Gutierrez L, Nessaiver MS, Carter WB, Bhargavan M, Lewis RS, Ioffe OB: Diagnostic accuracy of mammography, clinical examination, US, MR, imaging in preoperative assessment of breast cancer. Radiology 2004;233:830-849.

16 Brem RF, Ioffe M, Rapelyea JA, Yost KG, Weigert JM, Bertrand ML, Stern LH: Invasive lobular carcinoma: detection with mammography, sonography, MRI, and breast-specific gamma imaging. AJR 2009;192:379-383. 